\title{
FARM STRUCTURE AND COMMUNITY VIABILITY IN THE NORTHERN GREAT PLAINS
}

\author{
Jack C. Stabler and M.R. Olfert*
}

\begin{abstract}
The way in which the economic base of regional economies influences the viability of the communities that serve them has been a subject of inquiry for several decades. Many previous studies have been static in nature, thereby failing to capture the influence of changes in the base through time. Others, conducted over a period of years, have included only one (or a few) independent variables and have, consequently, provided a very selective view of the relationship.

In this paper, we investigate the relationship between the viability of 598 communities distributed among three agricultural economic regions in Saskatchewan over a 30-year period. A total of 37 variables describes each community at three points in time during the period studied.

A distinct positive association is observed between agricultural diversification, smaller farms, higher population density, and community viability. Conversely, a higher incidence of decline is associated with lack of diversification, larger farms, and lower population density.
\end{abstract}

\section{INTRODUCTION}

Determinants of the stability and growth of rural communities, the essential component for future rural economic development, are pursued by academics, community development practitioners, and policymakers. While simple prescriptions for success are unlikely, empirical studies of the relationship between community viability and the characteristics of its economic base have identified distinct patterns. A relationship that has received special attention is the one existing between community viability and the characteristics of agricultural production and organization in the immediate hinterland of the community.

Interest in the relationship between increasing concentration in agriculture and community well-being has a long history in agricultural economics. The pioneering work in this area was conducted by W. R. Goldschmidt in the early 1940s (Goldschmidt 1946; 1978). His analysis involved a comparison between two California communities, situated in like geographic environs, which he described as similar in terms of economic and demographic characteristics. Farms in the vicinity of one of the communities (Arvin) were large, characterized by absentee ownership and dependent upon hired labor. In the case of his second community (Dinuba), farms were smaller and family ownership more common.

*Professor and Lecturer, respectively, Department of Agricultural Economics, University of Saskatchewan. 
Goldschmidt reported numerous social and economic differences between the two communities and attributed these differences to the dissimilar agricultural structures in their immediate hinterlands. He concluded that an inverse relationship existed between corporate ownership and farm size on the one hand and desirable social and economic community characteristics on the other.

Goldschmidt's report generated a vigorous debate at the time and inspired numerous subsequent studies in the years that followed. The results of these studies have been mixed. Some claim to support Goldschmidt unequivocally, others in a qualified manner, while a third set report results inconsistent with Goldschmidt's findings. The literature on this subject is summarized in Nuckton et al. (1982), Swanson (1988), and Luloff and Swanson (1990). Recently, Goldschmidt's methodology, as opposed to his findings, has been questioned by Hayes and Olmstead (1984). They conclude that "his thesis that large farms spawn undesirable towns may be correct; but, because of methodological flaws, the study offers little support for this view" (Hayes and Olmstead 1984, 431).

Our review of the literature on this subject indicates that, in fact, few empirical studies actually provide a direct analysis of the relationship between farm size and community (i.e., small town) characteristics. None that we are aware of systematically study the relationship between farm structure and either the social or economic viability of rural communities. Instead, most focus on the relationship between farm size and some other variable(s) such as total population, family income, percent of population below the poverty line, quality of housing, class structure, or employment in service or manufacturing industries-usually defined on an area-wide rather than on a small community basis. A partial exception to the general pattern is found in Swanson's (1982) study of the relationship between number of farms and the populations of 520 rural Pennsylvania trade centers between 1930 and 1960. Swanson's approach is more in keeping with testing the relationship between farm size and community viability, but population is only one of the variables relevant to this question. A second partial exception is found in the five papers recently produced as the Congressional Research Reports through the Office of Technology Assessment (Swanson 1988). While it was not the intent in these studies to specifically inquire into the relationship between farm size and community viability, each did deal with one aspect or another of the relationship. Conclusions regarding comparative performance are not readily forthcoming, however, because different definitions, theoretical perspectives, and techniques of analysis were utilized for each study. Finally, a very useful recent study by Lobao (1990) does attempt to address this issue in a more comprehensive fashion. The generality of her study is limited, however, by the relatively short time frame (1970-80) and by the lack of correspondence of the periods covered by her agricultural and other data. 


\section{RELATED LITERATURE}

A substantial effort has been devoted to the analysis of trade-center change by regional scientists, regional economists, and economic geographers. The conceptual framework within which these studies are usually conducted is that of central place theory (Berry et al. 1988).

Using a comparative-static approach, communities within a region are sorted into functional classifications at two points in time. In a dynamic economy, the number of communities in any functional category may change through time, and the specific functions performed at each level could change as well. Frequently an attempt is made to interpret observed changes by reference to modified shopping patterns, changes in production, transportation, or distribution technology, or to the way in which public services are delivered. Often improved technology in agricultural production, leading to farm consolidation and rural depopulation, is mentioned as one of several factors contributing to changes in the structure of the trade-center hierarchy. However, we are unaware of any studies to date in this literature that have attempted to determine the specific influence of farm structures on community viability. Theoretical references in this area include White (1978), Parr (1979, 1981), Mulligan (1984), Scott (1986), and Berry et al. (1988). Representative empirical analyses are found in Borchert and Adams (1963), Hodge (1967), Stabler (1987), and Anding et al. (1990).

\section{APPROACH}

We began by acknowledging that the evolution of a trade-center system occurs in the context of a changing economic, technological, and social environment. Farm consolidation may be one of the important factors influencing community change, depending upon the type of agriculture practiced in the region and the importance of other basic rural industries such as mining and manufacturing. Some empirical studies have addressed the affect of farm size and ownership on community social viability. In this study, which covers three decades, the focus is on community economic viability, which we define as the ability of a rural community to maintain its functional position in the trade-center hierarchy as the system responds to changes in production and in transportation and communications technology and the redistribution of population that often follows.

An extension of the basic hypothesis also seems warranted. The structure of agricultural production may affect community viability through the influence of farm size, as many researchers have argued. In addition, however, the type of agricultural production may also affect community viability through the number 
and types of linkages with other industries that are technically possible. These linkage effects could be expected to differ as the nature and composition of agricultural production differed. Thus, the importance of farm consolidation in determining community viability may vary through time and from one region to the next (Hathaway 1960; Swanson 1988; Barkley 1990).

On the other hand, it seems plausible to argue that, within a region where communities are of the same general type, the influence of national and international forces would affect each community of a given class in a similar manner. Thus, changes in shopping patterns of rural dwellers or the introduction of new technologies for communications or distribution, for example, might be expected to affect all communities within the group of smallest centers in a regional tradecenter hierarchy in basically the same way. Communities in the next largest group might respond differently than those in the smallest category, but there does not seem to be any basis for arguing that the effect would occur differentially among communities within the same group.

These two propositions form the hypotheses that guide the work reported in the body of this paper. Stated somewhat more formally, our first hypothesis is that trade-center hierarchies alter through time in response to changing technologies and evolving preferences. These changes affect all communities systematically, though differentially among functional levels, in the trade-center system irrespective of their location. These trends may be observed by performing comparative static analyses of the trade-center system between two or more points in time. The second hypothesis is that regional differences in the structure of the agricultural economic base will affect the type of the adjustment to technological and behavioral influences. This can be investigated by determining whether observed regional differences in the pattem of trade-center change can be systematically associated with differences in the development of agricultural structures and/or practices between regions.

In order to use this approach, it is first necessary to identify a region with common economic, legal, and social institutions and within which most communities are of the same type-that is, agricultural trade centers. A second prerequisite is that agricultural production differs sufficiently between areas within this region so that different structures have developed. Then, if analysis of community change within the region reveals systematic differences between the dissimilar agricultural areas, these differences may be attributed to the underlying characteristics of agricultural production. 


\section{SETTING}

The province of Saskatchewan provides a near ideal setting for such an analysis. The availability of agricultural land provided the basis for initial settlement between the late 1890s and mid-1920s. By the end of the settlement era, the major portion of the southern half of the province was devoted to the production of small grains for export. As late as 1950, more than one-half the province's labor force was employed in agriculture, and grain exports accounted for approximately 80 percent of the value of products sold outside the province. Even today, 15 of Saskatchewan's 17 census divisions are classified as agriculture-dependent, with 20 percent or more of the labor force employed in agriculture (Fuller, Ehrensaft, and Gertler 1989). The province's two major cities are situated in the two nonagricultural-dependent census divisions. The remaining census division, number 18, covers the portion of the province that is forested.

The communities that were founded during the settlement period were created to provide for the farmers' needs and to facilitate the shipment of grain. To most Saskatchewan communities, these are still very important functions.

While wheat has always been the single largest export crop, regional specialization after World War II led to the near exclusive production of wheat and other small grains on the cultivated land in the southem and southwestem portion of the province. In the north, a more diversified agriculture persisted in which livestock, beekeeping, oilseeds, and specialty crops added variety to the traditional grain crops. Larger farms evolved in the south, and the specialization in grains was associated with a seasonal rather than a continuous labor requirement. The more diversified farms in the north remained smaller, and the requirement for labor is more continuous, although still with seasonal peaks. Family ownership remains common in both the north and the south. Only 3.2 percent of Saskatchewan's agricultural land is corporately owned (Statistics Canada 1986).

\section{DATA AND METHODOLOGY}

Our set of Saskatchewan communities consists of 598 incorporated and unincorporated places that, in 1961, had populations of 50 or more and were also listed in the 1986 census. The data used to describe and classify these centers include their populations, the number of commercial functions by SIC code, professional services, community and commercial infrastructure, and financial institutions. Information on population size was taken from the census and provincial medicare records; data on the number of commercial functions were obtained from Dun and Bradstreet's Reference Book plus provincial directories; and the 
location of infrastructure was collected from provincial records. Professional directories provided information on the location of members' offices. Information about banks was listed in Dun and Bradstreet in previous years and was obtained from the banks themselves for 1990. The Saskatchewan Credit Union Central provided a list of their member credit unions.

These data were used to group communities into functional classifications at the provincial level for 1961, 1981, and 1990 with the aid of a cluster-analysis program (Wishart 1987). The 1961 and 1981 classifications were taken from Stabler (1987). The 1990 classification represents an update of the earlier analysis. Descriptive names for the functional classifications are those commonly employed in central place studies. The experience of communities in the more diversified northem agricultural region was then compared with that of communities in the southern, more specialized agricultural region. The division between northern and southern zones was based on a group of agricultural variables as explained in a subsequent section.

\section{THE TRADE-CENTER SYSTEM: 1961, 1981, AND 1990}

The cluster-analysis program was used to assist in the assignment of communities to functional categories below the primary and secondary wholesaleretail levels. Communities in the latter two categories were subjectively classified. The raw data were standardized prior to clustering, and a similarity matrix was computed where the coefficients represent the squared Euclidean distance between communities. Clusters were formed using Ward's method, which minimizes the error sum of squares between the subject and its group centroid as fusion proceeds (Orloci 1967; Wishart 1987). Guided by a priori theory regarding the expected number of functional levels in a trade-center system (Berry et al. 1988) and previous studies of trade-center hierarchies in the northem Great Plains (Royal Commission on Agriculture and Rural Life 1957; Borchert and Adams 1963; Hodge 1965; Stabler and Williams 1973; Stabler 1987; Anding et al. 1990), we identified four distinct clusters within each of the three data sets. These clusters were selected by choosing those groups for which the distance between levels at which fusion occurred was greatest.

An iterative relocation option was then utilized to find local optima; a test of whether these local optima represented global efficiency was performed by reinitiating the iterative relocation procedure from several radically different starting classifications. The local optima proved to be very stable, although this procedure does not absolutely ensure identification of global optima (Wishart 1987). 
The validity of the groupings, including the primary and secondary wholesale-retail categories, was evaluated using multiple-discriminant analysis. Summary statistics of.the discriminant analysis are provided in Table 1.

TABLE 1

Evaluation by Discriminant Analysis of Six Functional Groups

\begin{tabular}{|c|c|c|c|}
\hline Evaluation & 1961 & 1981 & 1990 \\
\hline $\begin{array}{l}\text { Percent of grouped cases } \\
\text { "correctly" classified }\end{array}$ & 92.98 & 93.31 & 96.66 \\
\hline Wilks' Lambda ${ }^{a}$ & 0.0000225 & 0.0000063 & 0.0000022 \\
\hline \multicolumn{4}{|c|}{$\begin{array}{l}\text { Notes: Each six-level grouping was evaluated using the direct method, in which all vari- } \\
\text { ables are entered simultaneously and with each of five alternative stepwise methods. All } \\
\text { of the methods produced nearly identical results in which percentages of cases correctly } \\
\text { classified were within plus or minus } 1 \text { percent of the values in the table. Results using the } \\
\text { direct method are reported here. } \\
\text { 'The Wilks' Lambda statistics, which are ratios of within-group variance to total-sample } \\
\text { variance, indicate significance at the } 1 \text { percent level. }\end{array}$} \\
\hline
\end{tabular}

\section{OVERVIEW OF CHANGES IN THE PROVINCIAL TRADE- CENTER SYSTEM: $1961-1990$}

The number of communities in each functional classification and their summary descriptions for 1961, 1981, and 1990 are presented in Table 2. Between 1961 and 1981, a very substantial downward movement of communities from the middle categories occurred. In 1961, for example, there were 317 communities situated in the three clusters between the secondary wholesale-retail level and the lowest functional classification, the minimum convenience center. By 1981, the number occupying this interval had decreased to 188.

Between 1981 and 1990, there was some further downward movement of centers in the middle categories, but at a much slower rate. The number of communities in the three clusters between the secondary wholesale-retail and the minimum convenience levels declined from 188 in 1981 to 169 in 1990. What is most striking about the latter period is the pronounced decline of communities that were of complete shopping center status in 1981-only six centers (27 percent) remained in this category in 1990. A discussion of these phenomena and of the differential experience of communities by geographic area is the focus of the next section. ${ }^{1}$ 


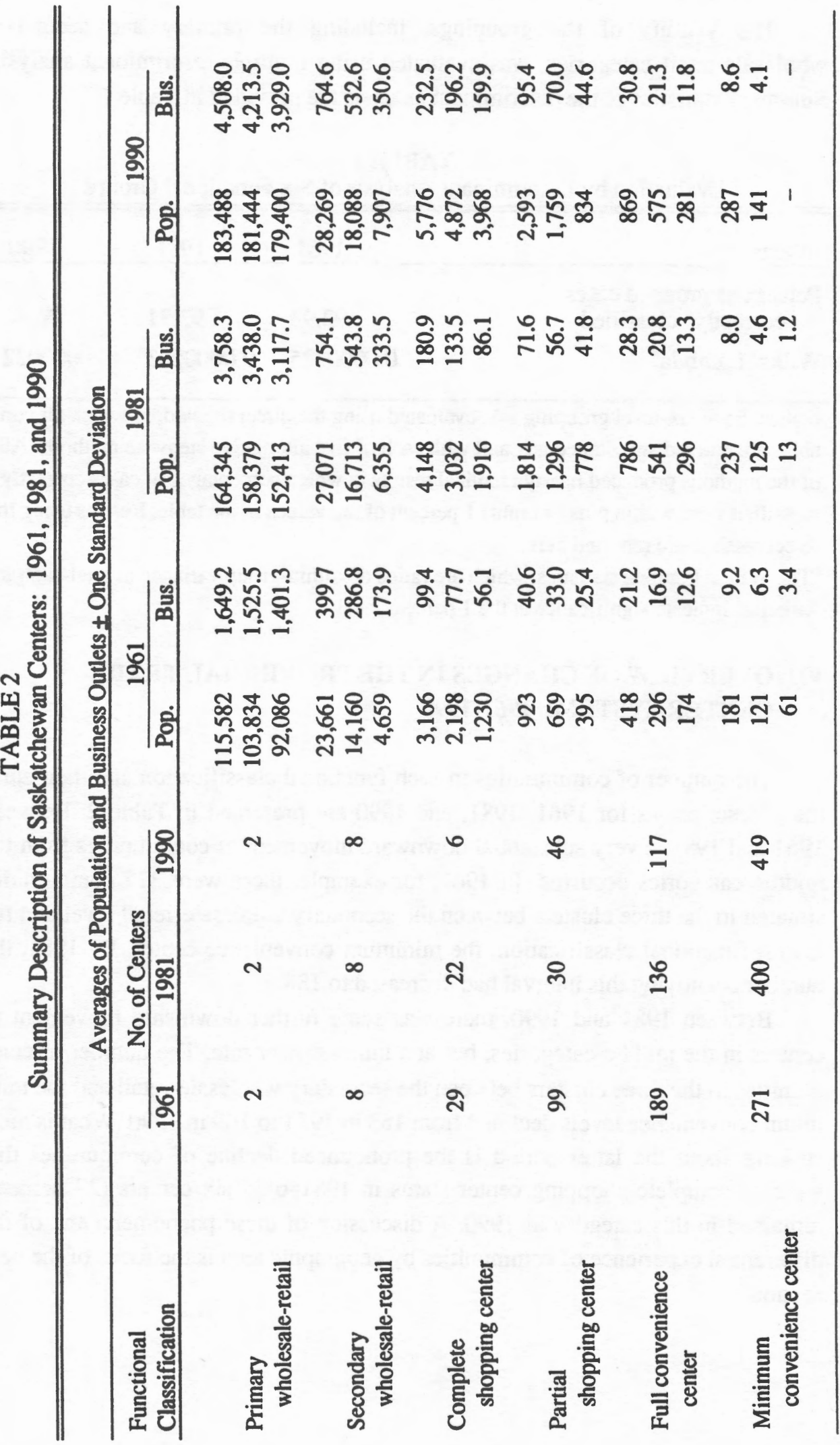




\section{AGRICULTURAL AREAS IN SASKATCHEWAN}

The viability of communities is determined primarily by the level and stability of the income of the population in the market areas surrounding each center. In Saskatchewan, the population in the rural areas surrounding these centers is still substantially dependent on agriculture, although the degree of this dependence, the mix of crops, and the size of farms differ between the north and the south.

Data were sought that would identify the degree of dependence on agriculture and the degree of diversification within agriculture by crop district. Diversification within agriculture could be expected to contribute to income stability. Income from nonagricultural sources could be expected to raise the level of income within the region and perhaps contribute to stability as well, if the cyclical pattem of nonagricultural activities differed from agriculture. The more diversified the economic base, the better the opportunity for local linkages to develop. Since diversified farms in Saskatchewan tend to be smaller, population densities in areas characterized by such farms are higher. This increases the size of the local labor force, which facilitates the attraction of linked activities.

To distinguish agricultural regions within the province, special tabulations of 1981 and 1986 census data were obtained from Statistics Canada on all sources of farm gross sales (imputed on the basis of actual sales, prices, and inventories) and on all income sources of farm families for the 20 crop district areas in the province. In addition, the census provides information on cultivated acres and farm size for each crop district. The crop districts were evaluated according to their position relative to the province in three alternative rating systems as described below.

Variables that formed the basis for rating the crop districts relative to the province include: (1) the percentage of imputed gross agricultural sales that originated from wheat and other small grains; (2) the percentage of imputed gross agricultural sales that originated from other field crops; (3) the percentage of imputed gross agricultural sales that originated from livestock; ${ }^{2}$ (4) the imputed gross value of agricultural sales per acre in the crop district; (5) average total acres per farm; and (6) the proportion of aggregate family income that is net farm income. Aggregation of scores for each crop district for variables 1, 2, 4, and 6; variables $1,2,3,5$, and 6 ; and variables $1,2,3$, and 6 formed three alternative methods of rating each crop district relative to the province. Crop districts that had aggregate scores above the provincial average in each of the three rating systems combined to form the northem area. ${ }^{3}$ The second group (the southem area) comprises all those crop districts with scores consistently well below the provincial average. The third group (the transition area) contained three crop districts 
that had mixed ratings in more than one of the rating systems at each point in time and/or through time. Fortunately, both the northem and southem areas were formed by combining contiguous crop districts. The three areas are shown in Figure 1.

In 1986 , farms in the southern area were roughly 50 percent larger than those in the north, based on cultivated acres, and approximately 63 percent larger than this based on average total acres. Farm size by agricultural area is shown for census dates between 1961 and 1986 in Table 3. Northern farms, which on average were 59 percent as large as those in the south in 1961, gained slightly during the following 25 years and were 62 percent the size of southern farms in 1986. Intensity of land use increased substantially in the north between these dates, however. Cultivated acres rose from 67 percent of the northern land base in 1961 to 77 percent in 1986 . In the south, cultivated total acres remained at approximately 70 percent through the entire period.

Community viability is also influenced by other rural economic activity, of course. In Saskatchewan, other resource-based industry is distributed more or less equally between agricultural areas. Three quarters of the province's 30-odd mines are found in the southern and transition areas, and most of the petroleum and natural gas production is accounted for by the south, with only limited amounts in the northem and transition areas. On the other hand, all forest-based activity (several sawmills, two pulp mills) is conducted in the north. There is some tourism in each area, but on balance the majority of the better tourist attractions are in the north. Furthermore, the northem resource base has generated more local linkages with other sectors than have the oil and gas and mining sectors in the south. In terms of total employment, the extractive industries together account for a sum that is less than 16 percent of the labor force employed in agriculture. There are no specific estimates for the amount of employment supported by tourism. Nevertheless, except for the few specific sites where mines, mills, or high-quality tourist attractions are situated, the economy of rural Saskatchewan is dominated by agriculture.

\section{COMMUNITY CHANGE BY AGRICULTURAL AREA}

The province's communities are distributed over these three areas as follows: 51 percent of the communities are in the north; 32 percent in the south; and 17 percent in the transition zone. Throughout the $1961-90$ period, all but a few of the province's communities experienced decline. Nevertheless, centers in the northern area have realized lower rates of decline than those in the southern area. 


\section{FIGURE 1}

\section{Agricultural Economic Areas in Saskatchewan}

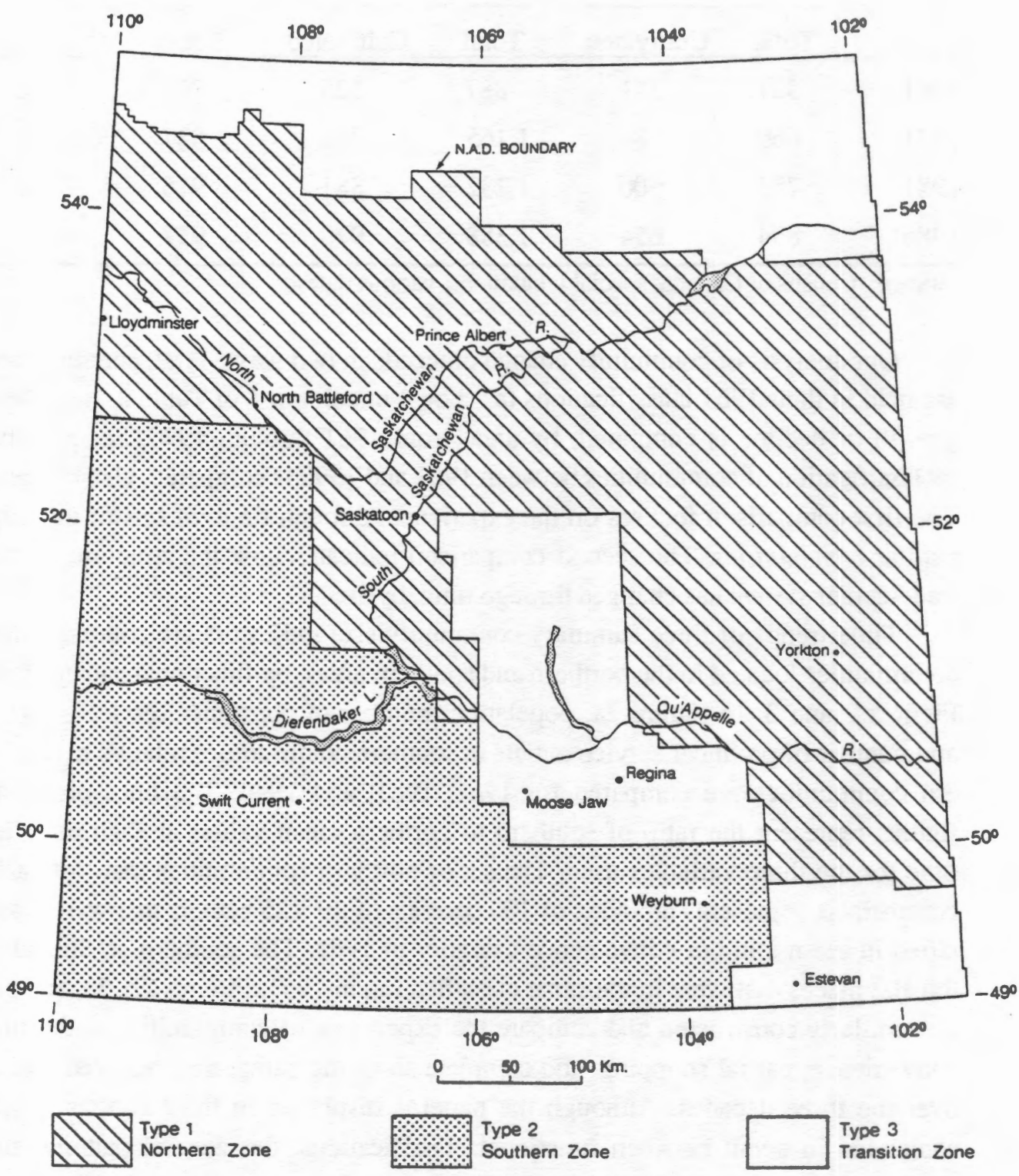


TABLE 3

Saskatchewan Farm Size by Agricultural Area: 1961-1986

\begin{tabular}{|c|c|c|c|c|c|c|}
\hline & \multicolumn{2}{|c|}{ North } & \multicolumn{2}{|c|}{ South } & \multicolumn{2}{|c|}{ Transition } \\
\hline & Total & Cultivated & Total & Cultivated & Total & Cultivated \\
\hline 1961 & 521 & 351 & 887 & 625 & 703 & 556 \\
\hline 1971 & 660 & 484 & 1,165 & 786 & 827 & 686 \\
\hline 1981 & 783 & 600 & 1,232 & 881 & 916 & 781 \\
\hline 1986 & 854 & 654 & 1,388 & 979 & 957 & 817 \\
\hline
\end{tabular}

Source: Census of Canada, special tabulations, various dates.

Our analysis of community change proceeds in two ways. First, communities are held in their 1961 classifications (as shown in column 1 of Table 2), and their growth or decline is compared, by area, from 1961 through 1990. Second, the reclassification of communities between 1961 and 1990 is compared, also by area. The first comparison focuses on the experience, through time, of sets of initially similar communities. The second comparison indicates how the structure of the trade-center system has changed through time, by area.

Time trends of three summary community size indicators are compared for communities located in the northem and southem areas, by functional category, in Figures 2 and 3. In Figure 2a, population, number of consumer service outlets, and number of producer service outlets in southem communities relative to northern communities are compared for 1961, 1981, and 1990. The lines on these figures represent the ratio of southern to northem mean values at each point in time for the three variables used. The set of northern communities that, for each comparison, represents an index of 100 consists of the 125 centers that were classified in the minimum convenience category in 1961. The southern set includes the 102 places that were in the same classification in 1961. Figures $2 b, 3 a$, and $3 b$ are similarly constructed and compare the experience of communities in the full convenience, partial shopping, and complete shopping categories, between areas, over the three decades. Although the patterns displayed in these figures differ somewhat in detail between functional classifications, the general pattems are similar and are remarkably consistent. The inescapable conclusion is that southern communities declined substantially relative to their northern counterparts over the three decades included in our analysis. Transition-zone communities are excluded from these figures in the interest of space. A set of detailed tables comparing changes in northem with southem communities at each date is available from the authors upon request. 
FIGURE 2A

Selected Characteristics of Minimum Convenience Centers:

Southem Relative to Northem

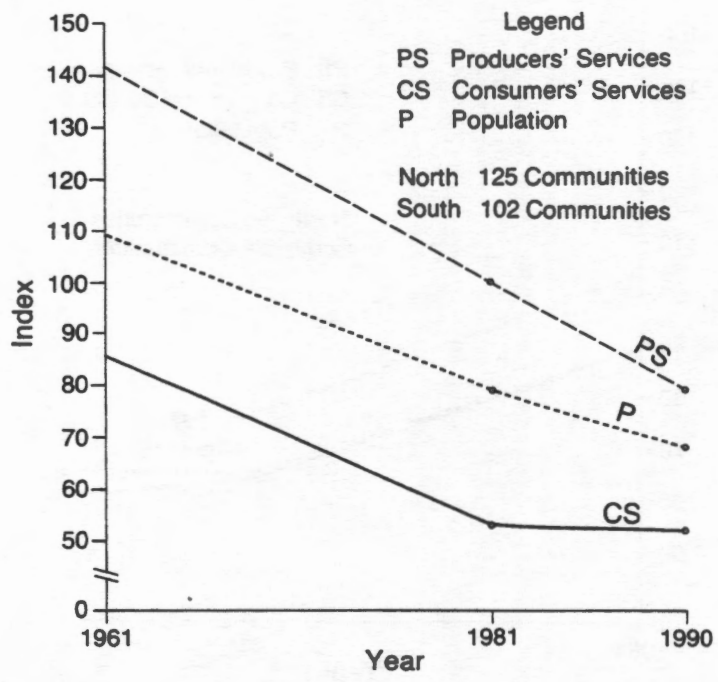

FIGURE 2B

Selected Characteristics of Full Convenience Centers: Southern Relative to Northern

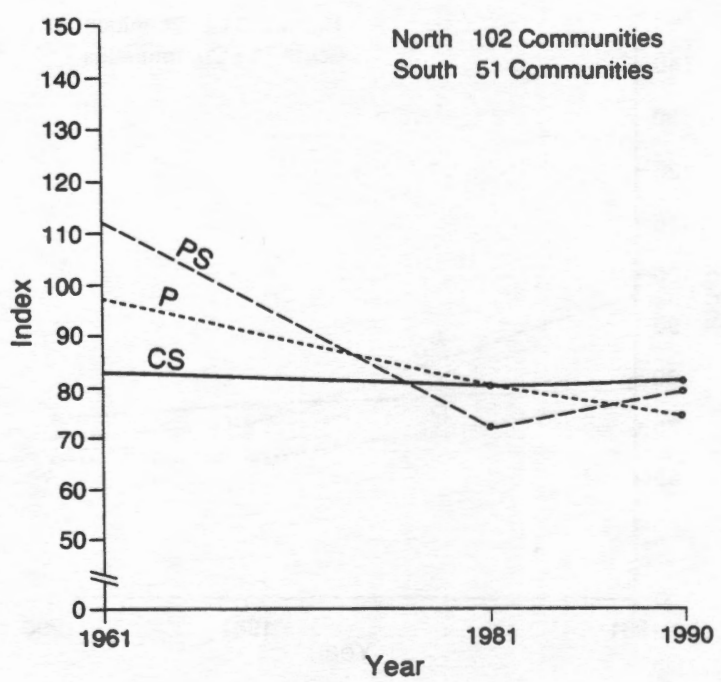


FIGURE 3A

Selected Characteristics of Partial Shopping Centers: Southem Relative to Northem

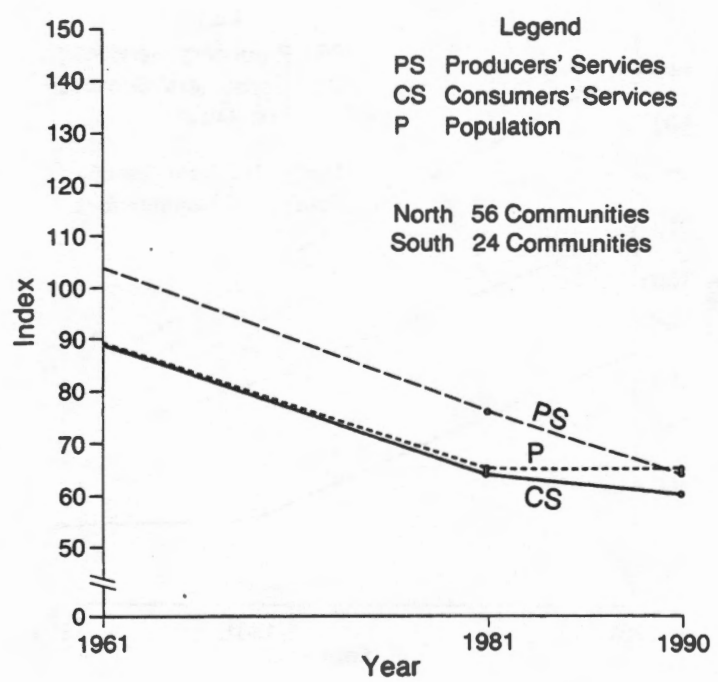

FIGURE 3B

Selected Characteristics of Complete Shopping Centers:

Southem Relative to Northem

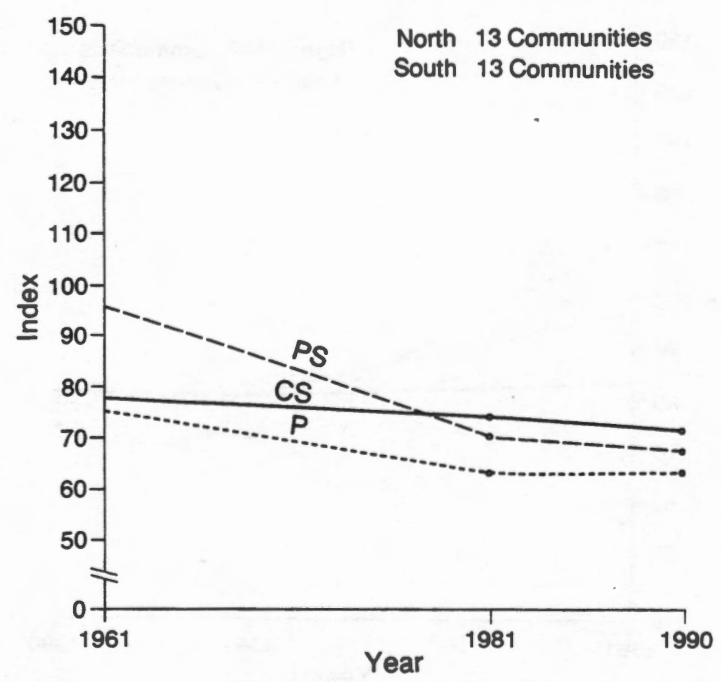


In our second comparison, changes in the structure of the trade-center system between areas are identified. In Table 4, the proportion of communities in each functional category at the beginning of the period that subsequently declined in status (D), retained its status (S), or rose (G) is shown by area. Rates of decline in the south consistently exceed those in the north for each of the four lowest functional categories between 1961 and 1990. For the subperiods, southem communities declined more rapidly than those in the north during the relatively prosperous 1961-81 period as well as during the less prosperous 1981-90 period. Only one instance can be identified in which decline in the north exceeded that in the south-the full convenience category between 1981 and 1990.

Previously, attention was drawn to the downward reclassification of complete shopping centers. Review of the CSC column in Table 4 reveals that downgrading began in the southem and transition zones following 1961 but did not affect complete shopping centers in the northern zone until after 1981. Following 1981, however, two thirds of the northern zone's (and six of the southem zone's remaining seven) complete shopping centers were reclassified. Spatial location within the hierarchy, i.e., proximity to larger centers, was not a significant factor in this process. Complete shopping centers were (and are) more or less evenly distributed across the province. The spatial pattern of their decline was much more closely associated with the type of agriculture practiced in the various zones, as it was for all of the lower levels of classifications.

A final perspective is provided in Table 5, which focuses on the shifting areal concentration of higher level communities within the trade-center hierarchy. In this table, the proportion of the province's communities classified in the top three (four) functional categories is identified by area for each of the three dates used in this analysis. Consistent with previous observations, the share of the province's viable communities in the north is shown to increase over time and to decrease in the south, based on either the top three or the top four functional classifications.

\section{OTHER FACTORS AFFECTING COMMUNITY VIABILITY}

A review of the detailed data upon which the comparisons in the previous section were based reveals several interesting structural differences between northern and southern communities. Southern communities, for example, were more specialized in business functions serving the agricultural industry in 1961 than their northem counterparts. In general, southem centers had greater numbers of farm equipment, bulk-fuel, for-hire transport, automobile (truck) sales, and auto (truck) repair outlets. Northern communities, on the other hand, had some- 


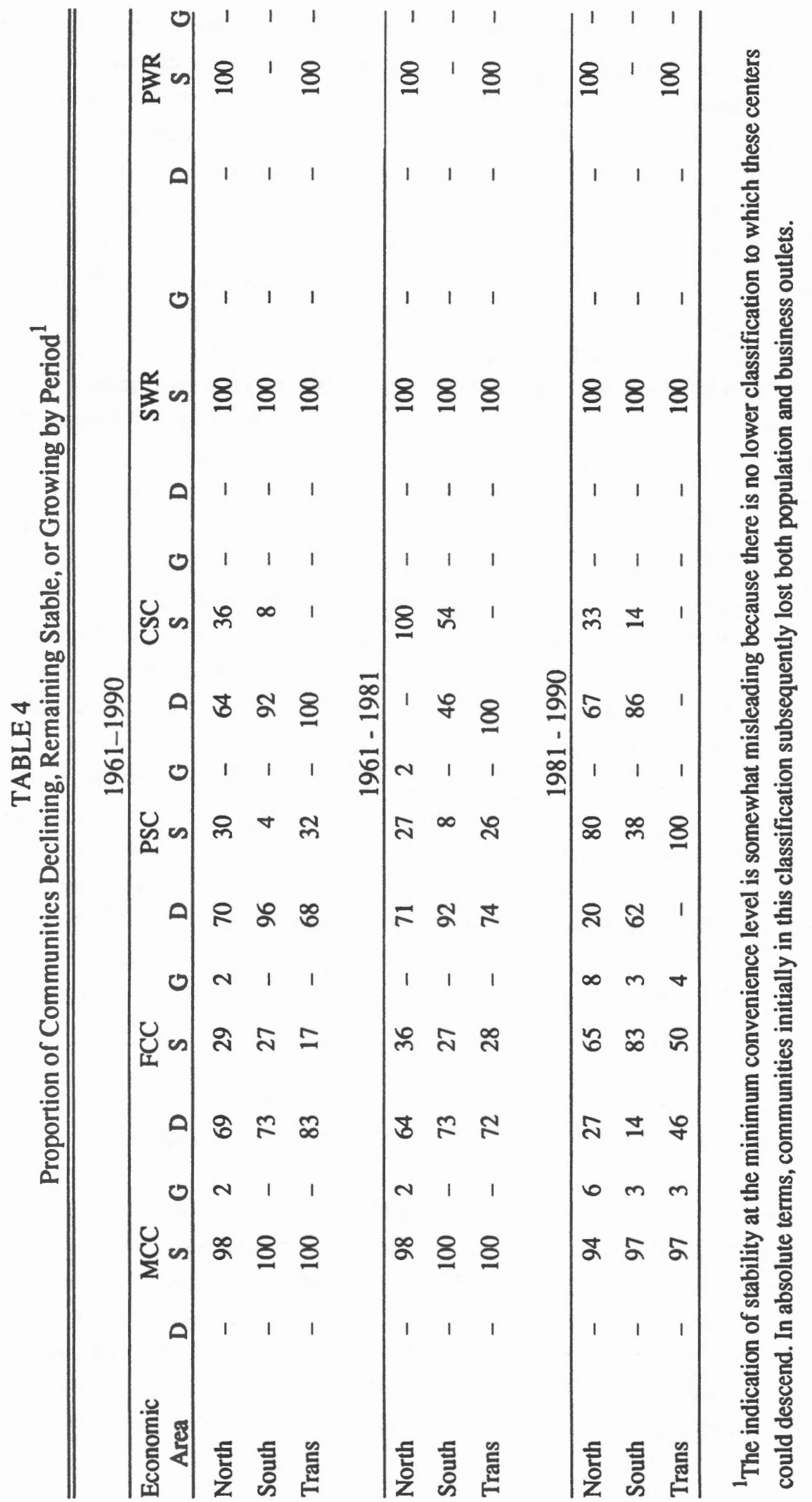


TABLE 5

Number and Percent of High-Level Centers in Each Economic Area: 1961,1981 , and 1990

A. Top Three Functional Categories

\begin{tabular}{lrrrrrr}
\hline $\begin{array}{l}\text { Economic } \\
\text { Area }\end{array}$ & \multicolumn{2}{c}{1961} & \multicolumn{2}{c}{1981} & \multicolumn{2}{c}{1990} \\
\hline North & 19 & 49 & 20 & 63 & 10 & 63 \\
South & 15 & 38 & 9 & 28 & 3 & 19 \\
Trans & 5 & 13 & 3 & 9 & 3 & 19 \\
& 39 & 100 & 32 & 100 & 16 & 100 \\
& & & & & & \\
\hline
\end{tabular}

B. Top Four Functional Categories

\begin{tabular}{lcccccc}
\hline Economic & \multicolumn{2}{c}{1961} & \multicolumn{2}{c}{1981} & \multicolumn{2}{c}{1990} \\
Area & No. & $\%$ & No. & $\%$ & No. & $\%$ \\
\hline North & 75 & 54 & 35 & 56 & 38 & 61 \\
South & 39 & 28 & 17 & 27 & 13 & 21 \\
Trans & 24 & 17 & 10 & 16 & 11 & 18 \\
& 138 & 100 & 62 & 100 & 62 & 100 \\
\hline
\end{tabular}

what larger populations in 1961 (except for the minimum convenience category), a greater number of manufacturing firms, and better developed consumer-service sectors. No systematic differences were apparent in the provision of public infrastructure.

Following 1961, northern communities increased their initial advantage in manufacturing through developing extended linkages with their more diversified agricultural base. A complement of business services developed around their growing manufacturing industries, and their consumer-service activities expanded as well. Between 1961 and 1990, the northern area gained 268 manufacturing plants, outside the largest city, while the southern area gained only 70 . Southem communities did not diversify, and their agricultural-service and consumer-service industries contracted as agricultural consolidation reduced the number of farms. Business services failed to develop because of the relative absence of manufacturing and other diversified activity. Although services to agriculture 
declined in the north, the contraction was not as rapid as in the south. Thus, by the end of the period, southem communities no longer demonstrated a relative dominance even in their former specialization. With little or no alternative development to offset the consolidation in agriculture, the population of southern minimum convenience, full convenience, and partial shopping centers declined. In the north, on the other hand, only minimum convenience centers experienced a loss of population.

While the expansion of manufacturing in the north can be attributed, in part, to the more diversified agriculture practiced there, a contributing influence can very likely be associated with widening differences in population densities. In 1961, there were 3.42 people per square mile in the south (outside of the wholesale-retail centers), which was 67 percent of the northern figure (5.08 people per square mile). By 1990 , the southern figure had fallen to 2.44 , which was 59 percent of the northern figure of 4.13 . The potential for production for local markets-initially less attractive in the south-worsened over the period under study. In addition, the possibility of being able to recruit a local labor force was obviously lower in the south at the beginning of the period and also declined relatively and absolutely with the passage of time. By 1990, the area from which a potential employer could recruit a labor force of a given size in the south was nearly 70 percent larger than that required in the north.

\section{CONCLUSIONS}

In this study we have compared the evolution of rural communities in two areas with different agricultural production patterns. Both areas are within a region characterized by common political, economic, legal, and social institutions. During the period under study, changes in production, transport, communications, and distribution technology-coupled with increasing urban-like preferences of rural dwellers-led to a more concentrated pattern for the provision of most private and public goods and of services for the entire region. Region-wide, the trade-center role of most communities within the lowest three functional categories in the trade-center hierarchy declined. In the top three categories, absolute growth was more common, although even within these groups, the growth was highly concentrated in the province's largest urban centers, with most other communities experiencing relative declines.

Within the region, agricultural production and farm size differed between the north and the south at the beginning of the study period, and this distinction became more pronounced during the three decades covered in our analysis. In both areas, farms became larger, but in the south extensive production of primarily 
wheat and other small grains continued and was accentuated. In the north, diversification into oilseeds, specialty crops, bees, and livestock was more common, and land use became relatively more intensive.

Community change within the region reflected evolving agricultural practices in each area. With consolidation, but no change in agricultural production patterns in the south, both population size and trade-center functions declined in the lowest three functional categories. In the north, consolidation was coupled with diversification and increasing intensity of land use, which supported a higher population density and provided the opportunity for expansion into agriculture-related and other manufacturing activity. Except for minimum convenience centers, the average population size of northern communities increased in every functional category, and relative to southem communities, the decline in their trade-center functions was less pronounced. Consequently, the percentage of the province's communities in the top three functional categories that are located in the north increased from 49 percent to 63 percent between 1961 and 1990, while the percentage in these categories accounted for by the southern region declined from 38 percent to 19 percent.

These results definitely link agricultural production and farm size with community change, although in a more complex way than is usually envisaged. First, it is necessary to separate the effect of dissimilar agricultural production and farm size from other general, but pervasive, influences attributable to changing technologies and shifts in preferences. Furthermore, community viability is seen to be sensitive to the particular type of changes in the agricultural sector. Farm consolidation, accompanied by diversification, for example, coincided with an expansion of processing and manufacturing activity in the northern zone. In the period covered by this study, 70 percent of Saskatchewan's new rural manufacturing plants were located in the northern zone. Approximately 25 percent of these plants were linked with agriculture in some way. The majority of the remainder were attracted by the availability of a dependable labor force and lower land costs. This development partially offset the effect of agricultural consolidation on population size. In the southern zone, on the other hand, consolidation, without diversification, was associated with a greater population loss and a more rapid and more pronounced decline of rural communities.

Some peripheral issues remain. In some studies, the influence of corporate ownership of agricultural holdings is argued to be detrimental to community viability because managers and employees may not identify with, shop at, or participate in community activities. This proposition has not been addressed in our study because of the limited extent of corporate ownership in Saskatchewan. We have demonstrated, however, that corporate ownership is not a necessary condition for loss of viability. Consolidation and lack of diversification, even with 
family ownership, are seen to be sufficient to produce community decline. Furthermore, in other studies, the social dimension of community change is emphasized, while our study focuses on the economic aspects of trade-center change. It seems reasonable to infer, however, that a loss of social vitality accompanied the loss of economic viability since many social structures depend upon number of people in the same way that commercial activities depend upon population size to satisfy market-threshold requirements.

\section{ENDNOTES}

1. Extensive, detailed research reports on community change, off-farm employment, and rural manufacturing activity form the basis of the analysis summarized here. These research reports, listed in the references under Stabler and Olfert, are available from the authors on request.

2. Livestock sales excluded beef cattle because it was not possible to distinguish cow-calf operations, which require relatively little labor, from feeder-cattle operations, which are somewhat more labor intensive.

3. For variables 2,3 , and 4 , the ratio comparing the crop district with the province was formed with the crop-district value in the numerator and the provincial average in the denominator. That is, a proportion of sales originating from other crops or from livestock in excess of the provincial average is considered to make a positive contribution to the economic viability of communities in that district. Likewise an above average sales per acre was considered a positive attribute. For the other three variables (percent of total sales originating from wheat and small grains, net farm income as a percentage of aggregate family income, and farm size), the provincial average was the numerator and the value for the crop district was the denominator. In the first instance, heavy concentration in wheat and small grains represents an absence of diversification that leaves the area more vulnerable to long-term decreases in the prices of these commodities and more likely to pursue very land-extensive agriculture. In the case of net farm income as a percentage of aggregate family income, a score for the crop district above the provincial average was considered a negative attribute because it represents a lack of diversification of farm family labor into alternative (nonfarm) uses. A larger than average farm size was also considered a negative attribute because of the implications for size of farm population and thus community support. 


\section{REFERENCES}

Anding, Thomas L., et al. Trade Centers of the Upper Midwest: Changes from 1960 to 1989. Minneapolis: Hubert H. Humphrey Center, 1990.

Barkley, Andrew P. "The Determinants of the Migration of Labor Out of Agriculture in the United States: 1940-85." American Journal of Agricultural Economics 72 (1990): 567-573.

Berry, Brian J. L., et al. Market Centers and Retail Location: Theory and Applications. Englewood Cliffs, N.J.: Prentice Hall, 1988.

Borchert, John R., and Russell B. Adams. Trade Centers and Tributary Areas of the Upper Midwest. Minneapolis: University of Minnesota, 1963.

Dun and Bradstreet. Reference Book. Toronto: June 1961, 1981, 1990.

Fuller, Tony, Philip Ehrensaft, and Michael Gertler. Sustainable Rural Communities in Canada. Saskatoon: University of Saskatchewan, 1989.

Goldschmidt, Walter R. Small Business and the Community: A Study in Central Valley of California on Effects of Scale of Farm Operations. Report of the Special Committee to Study Problems of American Small Business. Washington, D.C.: 79th Congress, 2nd Session, 1946.

As You Sow: Three Studies in the Social Consequences of Agribusiness. Montclair: Allenheld Osmun and Co., 1978.

Hathaway, Dale E. "Migration from Agriculture: The Historical Record and Its Meaning." American Economic Review 50 (1960): 379-391.

Hayes, Michael N., and Alan L. Olmstead. "Farm Size and Community Quality:

Arvin and Dinuba Revisited." American Journal of Agricultural Economics 66 (1984): 430-436.

Hodge, Gerald. "The Prediction of Trade Center Viability in the Great Plains." Papers, Regional Science Association 15 (1965): 87-115.

Lobao, Linda M. Locality and Inequality: Farm and Industry Structure and Socioeconomic Conditions. Albany: SUWT Press, 1990.

Luloff, A. E., and Louis E. Swanson. American Rural Communities. Boulder, Colo.: Westview Press, 1990.

Mulligan, Gordon F. "Agglomeration and Central Place Theory: A Review of the Literature." International Regional Science Review 9 (1984): 1-42.

Nuckton, C. F., R. I. Rochin, and D. Gwynn. "Farm Size and Rural Community Welfare: An Interdisciplinary Approach." Rural Sociology 47 (1982): 32-46.

Olfert, M. R., and Jack C. Stabler. "The Employment of Farm Women." University of Saskatchewan, Department of Agricultural Economics, 1992.

Orloci, L. "An Agglomerative Method for Classification of Plant Communities." Journal of Ecology 55 (1967): 193-206. 
Parr, John B. "Regional Economic Change and Regional Spatial Structure: Some Interrelationships." Environment and Planning A 11 (1979): 825-837. . "Temporal Change in a Central Place System." Environment and Planning A 13 (1981): 97-118.

Saskatchewan, Royal Commission on Agriculture and Rural Life. Service Centers. Regina: Queen's Printer, 1957.

Scott, A. J. "Industrial Organization and Location: Division of Labor, the Firm and Spatial Process." Economic Geography 62 (1986): 214-231.

Stabler, Jack C. "Trade Center Evolution in the Great Plains." Journal of Regional Science 27 (1987): 225-244.

Stabler, Jack C., and M. R. Olfert. Restructuring Rural Saskatchewan: The Challenge of the 1990s. Regina, Saskatchewan: Canadian Plains Research Centre, 1993.

Stabler, Jack C., M. R. Olfert, and Murray Fulton. The Changing Role of Rural Communities in an Urbanizing World: Saskatchewan 1961-1990. Regina, Saskatchewan: Canadian Plains Research Centre, 1992.

Stabler, Jack C., and Peter R. Williams. The Dynamics of a System of Central Places. Geographical Papers, 22. Reading: University of Reading, 1973.

Statistics Canada. Census of Canada. 1961, 1971, 1981, and 1986. Special Tabulations.

. Census of Agriculture - Saskatchewan, 1986. No. 96-1110, Table 1.

Swanson, Louis E. "Farm and Trade Center Transition in an Industrial Society: Pennsylvania, 1930-1960." Unpublished Ph.D. diss., Department of Rural Sociology, University of Wisconsin, Madison, 1982.

, ed. Agriculture and Community Change in the U.S.: The Congressional Research Reports. Boulder, Colo.: Westview Press, 1988.

White, Roger W. "The Simulation of Central Place Dynamics: Two Sector Systems and the Rank-Size Distribution." Geographical Analysis 10 (1978): 201-208.

Wishart, D. Clustan User Manual. 4th ed. Edinburgh: Edinburgh University, 1987. 